\title{
MICROBIOLOGICAL STATUS AND OXIDATION PROPERTIES OF MINCED CHICKEN BREAST MEAT TREATED WITH DIFFERENT CONCENTRATIONS OF ALLYL-ISOTHIOCYANATE
}

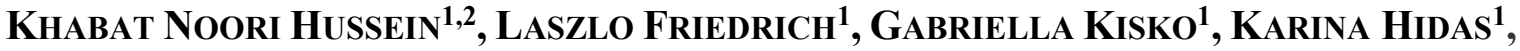 \\ CSABA NEMETH ${ }^{3}$, ISTVAN DALMADI ${ }^{1}$ \\ ${ }^{1}$ Szent Istvan University, Faculty of Food Science, Department of Refrigeration and \\ Livestock Products' Technology, Budapest, Hungary \\ ${ }^{2}$ University of Duhok, College of Agriculture, Department of Animal Production, Duhok, \\ Kurdistan Region, Iraq \\ ${ }^{3}$ Capriovos Ltd., Szigetcsep, Hungary. \\ khabat.noori@uod.ac
}

\begin{abstract}
Due to its biological composition, poultry meat is perishable by nature and susceptible to quality deterioration such as microbial spoilage and oxidation changes. Meat and meat products with healthy, extended shelf-life and good organoleptic properties are highly demanded by consumers. In current study, the antimicrobial and antioxidant effects of allyl-isothiocyanate (AITC) as a natural additive on raw chicken meat during chilling storage were determined. For this purpose, samples of minced were treated with different concentrations of AITC $(100,200,300$ and $500 \mathrm{ppm})$ and control no AITC added, the samples packaged and stored for 8 days at $4{ }^{\circ} \mathrm{C}$. Fluctuations with no significant effect were noticed in TBARS values during the storage period. Simultaneously, AITC with higher concentration showed lower mesophilic aerobic counts compared to control and meat containing a low concentration of AITC. Moreover, compared to the beginning of storage, AITC decreased water holding capacity (WHC) of meat this can affect other physicochemical properties of meat. Further study needed to determine the effect of AITC on the physicochemical properties of meat and food products.
\end{abstract}

Keywords: chicken meat, allyl-isothiocyanate, lipid oxidation, microbiological properties, refrigeration storage

\section{INTRODUCTION}

Poultry meat and particularly chicken is the cheapest commercially produced meat, it is supposed to have an increase in consumption by $34 \%$ by 2018 (JUNG ET AL., 2011). Poultry meat is highly perishable in nature, it is prone to quality deterioration, which affects quality characteristics and can lead to undesirable reactions because it contains higher levels of unsaturated fatty acids compared to red meat (LUCERA ET AL., 2012). The principles of meat preservation are mainly associated with preventing or delaying microbial spoilage and chemical action and avoiding as far as possible any organoleptic changes. Therefore, if the meat and meat products are not preserved and handled properly, it could be a common vehicle for foodborne diseases, enhanced rancidity and it compromises the nutritional quality. Eventually, it influences product acceptance by consumers causing food insecurity and economic loss. The consequences of microbial spoilage and oxidation changes can be limited or inhibited using natural additives of plant origin which have been used as an alternative to synthetic food additives. These natural preservatives possess properties for extending the shelf-life and improving product quality. Allyl isothiocyanate (AITC) $\left(\mathrm{CH}_{2}=\mathrm{CH}-\mathrm{CH}_{2}-\mathrm{N}=\mathrm{C}=\mathrm{S}\right)$ is one of many natural non-phenolic volatile sulphur compounds that are found in the seeds, stems, leaves, and roots of cruciferous plants (Brassicaceae family), its alos are found in horseradish, cabbage, wasabi, brussels sprouts, broccoli and cauliflower (CORRALES ET AL., 2014). The volatile oil of mustard consists almost entirely of AITC (93-99\%) (THOMAS ET AL., 2004). It is legalized to be applied as food additives and GRAS flavoring agent in different food systems in several countries such as USA and 
Japan. It has been noted as natural flavoring, it could possess antioxidant characteristics and it is applied as an antispoilage agent in food at low concentrations (EFSA, 2010) It has been reported that the effectiveness of AITC in inhibiting bacteria at all growth stages support its application in food preservation (LIN ET AL., 2000). The aim of current study was to investigate the influence of different concentrations of AITC on the microbiological status and oxidation properties of minced chicken breast meat.

\section{MATERIAL AND METHOD}

Fresh chicken breast meat 24 hours' post-mortem was obtained from a local slaughterhouse (Budapest-Hungary) and transported to laboratories (Faculty of Food Science - SZIU). The meat then was cut and minced (free from bone, connective tissue, skin and visible fat), homogenized and divided into samples of four groups. Control (sunflower oil only) and three treatments were mixed with 100, 200, 300 and $500 \mathrm{ppm}$ AITC and 5\% oil. Then the samples were placed in polyethylene bags, packaged and stored at $4 \pm 0.5{ }^{\circ} \mathrm{C}$ for up to 8 days. The samples were then taken at different time intervals for different analyses.

\section{Lipid oxidation}

Lipid oxidation was measured by analysing TBARS using the method described by GANHÃO ET AL. (2011), slightly modified as follows. Chicken meat of $4 \mathrm{~g}$ was dispensed in mixing glass tubes and homogenized with $20 \mathrm{~mL}$ of distilled water. Then $5 \mathrm{~mL}$ of $25 \%$ trichloroacetic acid (TCA) was added to the mixture then homogenized with a centrifuge $5,000 \mathrm{rpm}$ for $10 \mathrm{~min}$. The homogenized aliquot supernatant was filtered through filter paper (diameter $11 \mathrm{~cm}$ ). Then, $3.5 \mathrm{~mL}$ of this solution was removed and added to $1.5 \mathrm{~mL}$ of $0.6 \%$ thiobarbituric acid (TBA) $(0.02 \mathrm{M})$. The tubes were placed in a boiling water bath and kept at $100{ }^{\circ} \mathrm{C}$ for $30 \mathrm{~min}$. After cooling, absorbance readings were taken for glass cuvette containing samples against the blank (3.5 mL 25\% TCA and $1.5 \mathrm{~mL} \mathrm{0.6} \mathrm{M} \mathrm{TBA).}$ with usning a Spectrophotometer (U2900-HITACHI Ltd., Tokyo, Japan) at $532 \mathrm{~nm}$ against a blank. TBARS were expressed as mg malonaldehyde (MDA equivalent) /1000 g sample.

\section{Microbiological analysis}

Microbiological analysis of meat was carried out through analysing population of aerobic mesophile counts after treatments and during storage. Ten grams of each sample in triplicate were measured aseptically into sterile stomacher begs, stomachered for $2 \mathrm{~min}$ with $90 \mathrm{~mL}$ of MRD diluent, and 10-fold serial dilutions were made. The appropriate dilutions were pour plated on nutrient agar. Plates were then incubated for $48 \mathrm{~h}$ at $30^{\circ} \mathrm{C}$, and the colonies were counted by a colony counter. Microbial data were transformed into logarithms and the results were expressed as (LogCFU/g) (APHA 2001).

\section{WHC Measurement}

Measurement of WHC was performed using a press technique explained by OzTAN AND VURAL (1993) with a slight modification. A sample (0.25-0.32 g) was placed on a filter paper (Whatman no. 10), set between 2 Plexiglas plates and pressed for $5 \mathrm{~min}$ by a $500 \mathrm{~g}$ weight. The outlined area of the expressible liquid and the pressed meat film were traced. The filter paper was then placed in an oven for $10 \mathrm{~min}$ followed by $5 \mathrm{~min}$ in a desiccator. WHC was calculated as a ratio of meat film area-to-total liquid area. It should be noted that a higher expressible liquid area was related to reduced WHC (higher drip loss). 


\section{RESULTS AND DISCUSSION}

\section{TBARS values}

The result from lipid oxidation is presented in Figure 1. Fluctuations with no significant effect were noticed in TBARS values during the storage period. Protective effect of 200 and 300 ppm AITC against lipid oxidation were seen by keeping TBA scores lower than $2 \mathrm{mg} \mathrm{MDA} / \mathrm{kg}$ during storage $(P<0.05)$. It has been reported that TBA $\geq 5 \mathrm{mg} \mathrm{MDA} / \mathrm{kg}$ meat comprise the threshold for detecting off-flavour for humans (KARABAGIAS ET AL., 2011).

\section{Microbiological analysis}

The results from the microbiological effect of all treated samples, 100, 200, 300 and 500 ppm are presented in Figure 2. It was observed that the meat containing higher concentration AITC showed lower mesophilic aerobic counts compared to control and meat containing a low concentration of AITC. Similar to current study, NADARAJAH ET AL. (2005) tested commercial AITC in fresh ground beef. They observed that the total bacterial population increased from 3.6 to $7.3 \log ^{10} \mathrm{CFU} / \mathrm{g}$ in the control samples, they also found that the bacterial population reached $6.5 \log { }^{10} \mathrm{CFU} / \mathrm{g} 0.5 \mathrm{~mL}$ for AITC-treated samples after storage at $4{ }^{\circ} \mathrm{C}$ for 21 days. The antimicrobial mechanism of isothiocyanates has not yet been fully elucidated, it is believed to be associated with sulfhydryl-containing enzymes (LUCIANO AND HOLLEY, 2009). It can be highlited the AITC has potenial to extend shelf-life of fresh meat.

\section{Water holding capacity}

The WHC results are presented in Figure 3. The AITC did show some effect on the WHC chracterisics of meat compared to untreated samples especially with $300 \mathrm{ppm}$. However, $500 \mathrm{ppm}$ showed decreased WHC compared to first day of storage. Additonally, a decrease in WHC of meat can affect other physicochemical properties of meat such as; colour lightness, a decline in $\mathrm{pH}$, ionic strength, increase oxidation) (HUFF-LONERGAN AND LONERGAN, 2005).

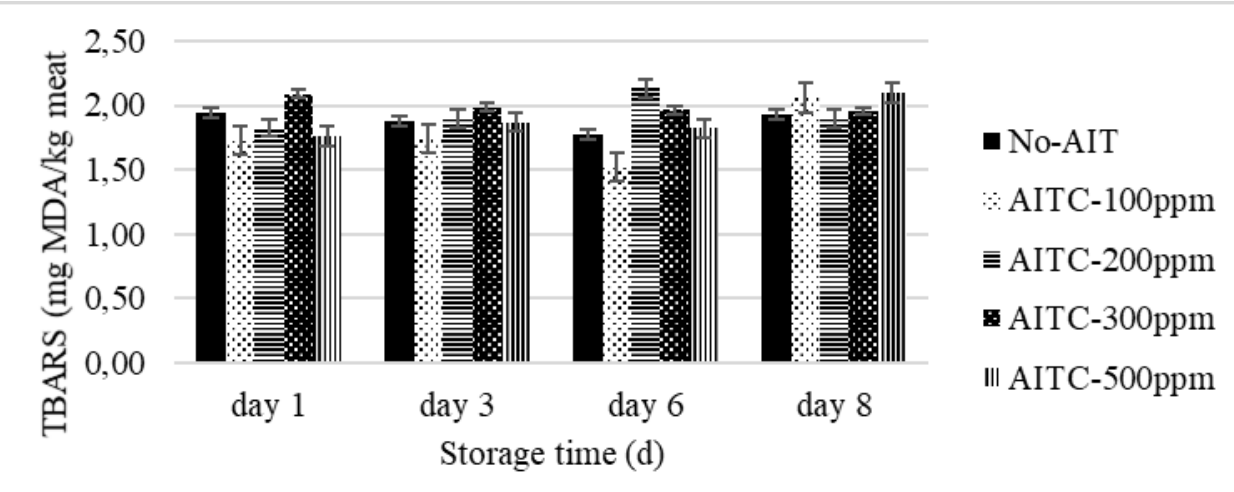

Figure 1: The influence of different concentrations of AITC on TBARS of fresh chicken meat stored for 8 days at $4^{\circ} \mathrm{C}$ 


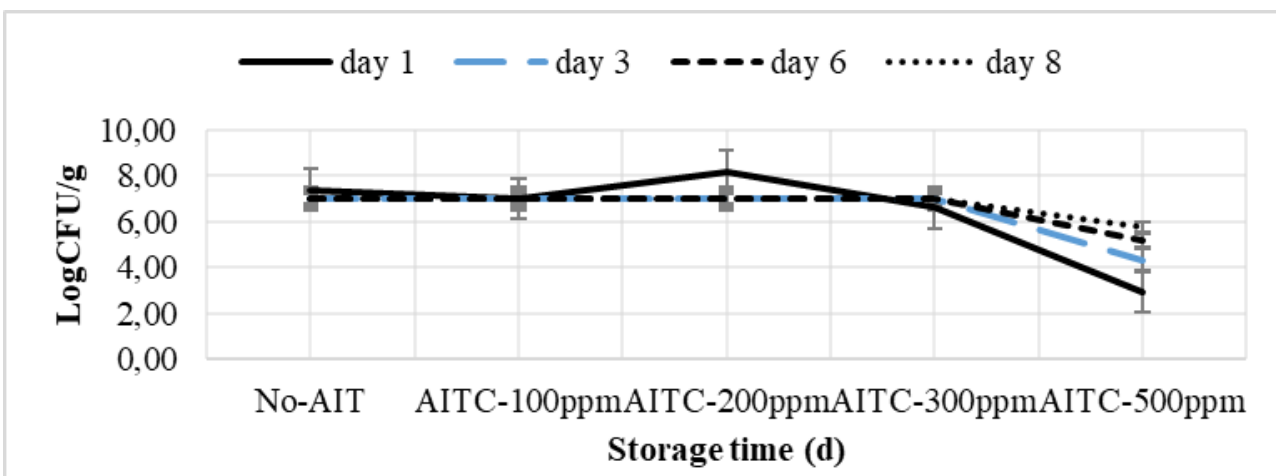

Figure 2: Efficacy of different concentrations of AITC on aerobic mesophilic counts of chicken meat stored for 8 days at $4{ }^{\circ} \mathrm{C}$

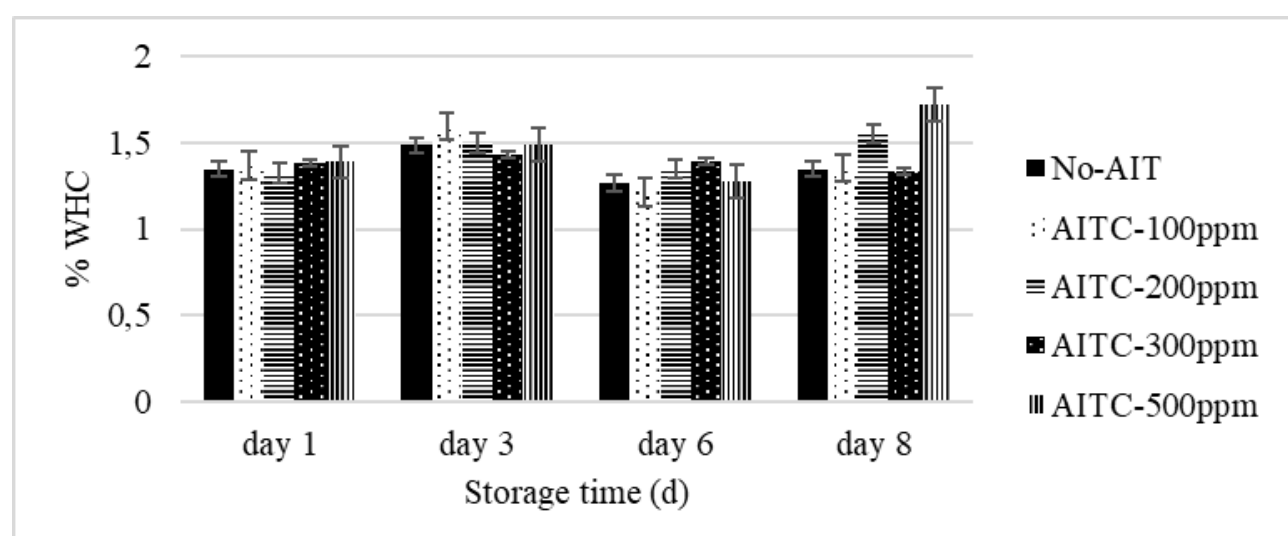

Figure 3: The influence of different concentrations of AITC on WHC of fresh chicken meat stored for 8 days at $4^{\circ} \mathrm{C}(p<0.05)$

CONCLUSIONS

The application of various concentrations of AITC into the chicken breast had shown the fluctuations with no significant effect in TBARS values during the storage period. Additionally, AITC of higher concentration showed lower mesophilic aerobic counts compared to control and other meat groups. Moreover, compared to the beginning of storage, AITC decreased WHC of meat. Future studies are required to determine the effect of AITC on the physicochemical properties of meat and food products.

\section{ACKNOWLEDGEMENTS}

The authors would like to thank laboratory technicians and the Doctoral School of Food Sciences (SZIU) for their support. Supported by the EU and European Social Fund, Project No. EFOP-3.6.3-VEKOP-16-2017-00005.

\section{REFERENCES}

APHA (2001): Compendium of methods microbiological examination of foods, 4th ed. American Public Health Association, Washington, DC

CorRales, M., Fernández, A., HAN, J.H. (2014): Antimicrobial packaging systems. In: Han, J.H. (Ed.): Innovations in food packaging. Elsevier Academic Press, San Diego. pp. $133-170$. 
EFSA (2010): Scientific opinion on the safety of allyl isothiocyanate for the proposed uses as a food additive. EFSA Journal 8(12): 1943 [40 pp.], DOI: 10.2903/j.efsa.2010.1943

GANHÃO, R., Estévez, M., Morcuende, D. (2011): Suitability of the TBA method for assessing lipid oxidation in a meat system with added phenolic-rich materials. Food Chem 126: 772-778.

HuFF-LONERGAN, E., LONERGAN, S.M. (2005): Mechanisms of water-holding capacity of meat: The role of postmortem biochemical and structural changes. Meat Science 71: 194204.

Jung, Y., Jeon, H. J., Jung, S., Choe, J. H., Lee, J.H., HeO, K.N., Kang, B.S., Jo, C. (2011): Comparison of quality traits of thigh meat from Korean native chickens and broilers. Korean J. Food Sci. Anim. Resour. 31: 684-692.

Karabagias, I., BadeKa, A., Kontominas, M.G. (2011): Shelf life extension of lamb meat using thyme or oregano essential oils and modified atmosphere packaging. Meat Sci 88: 109-116.

Lin, C.M., Preston, J.F., WeI, C.I. (2000): Antibacterial mechanism of allyl isothiocyanate. J Food Prot. 63(6): 727-34.

Lucera, A., Costa, C., Conte, A., Del Nobile, M.A. (2012): Food applications of natural antimicrobial compounds. Frontiers in Microbiology 3: (287), pp. 1-13.

LuCIANO, F.B., Holley, R.A. (2009): Enzymatic inhibition by allyl isothiocyanate and factors affecting its antimicrobial action against Escherichia coli O157:H7. Int J Food Microbiol 131: 240-245.

NADARAJAH, D., HAN, J.H., HOLley, R.A. (2005): Inactivation of Escherichia coli O157:H7 in packaged ground beef by allyl isothiocyanate. Int J Food Microbiol 99: 269279.

OzTAN, A., Vural, H. (1993): A study on the changes of water holding capacity and the free water proportion of beef. Gida 18: 29-33.

Thomas, J., Kurivilla, K.M., HrideeK, T.K. (2004): Mustard. In: Peyer, K.V. (Ed.): Handbook of herbs and spices, vol. 2. Woodhead Publishing Ltd and CRC Press LLC, NW Boca Raton, Florida, p. 360. 